\title{
Sex differences in the neurochemical and functional effects of MDMA in Sprague-Dawley rats
}

\author{
Q. David Walker • Christina N. Williams • \\ Rakesh P. Jotwani • Samuel T. Waller • \\ Reynold Francis • Cynthia M. Kuhn
}

Received: 13 January 2006 / Accepted: 26 July 2006 / Published online: 23 September 2006

(C) Springer-Verlag 2006

\begin{abstract}
Rationale 3,4-Methylenedioxymethamphetamine (MDMA; "Ecstasy") use has been associated with acute toxicities and persistent depletion of the neurotransmitter serotonin (5-HT).

Objectives This study investigates whether sex differences in the acute and long-term effects of MDMA exist.

Methods Male and female rats received saline or $15 \mathrm{mg} / \mathrm{kg}$ MDMA, ip, bid for 4 days. Temperature was monitored on days 1 and 4 . Locomotor activity was measured in a second cohort of animals on days 1 and 4 and after recovery on day 14. The effects of MDMA on performance in a plus maze task and brain levels of serotonin (5-HT) and the serotonin metabolite 5-hydroxyindoleacetic acid (5-HIAA) were determined in a third cohort of animals 2 weeks after the last MDMA treatment.

Results Locomotor activity and temperature increased after MDMA administration on day 1 . The drug-induced increases in temperature but not locomotion attenuated with repeated MDMA administration. Male and female MDMA-treated rats spent less time in the open arms of the elevated plus maze and had less 5-HT and 5-HIAA in all brain regions 2 weeks after the end of treatment. Temper-
\end{abstract}

Funding: DA 09079. Christina N. Williams was supported by an RJR-Leon Golberg postdoctoral fellowship and ES07031.

Q. D. Walker · C. N. Williams · R. P. Jotwani $\cdot$ S. T. Waller $\cdot$

R. Francis • C. M. Kuhn

Department of Pharmacology and Integrated Program

in Toxicology, Duke University Medical Center,

Durham, NC 27710, USA

C. M. Kuhn $(\square)$

Department of Pharmacology, Duke University,

Box 3813, Durham, NC 27710, USA

e-mail: ckuhn@duke.edu ature effects of MDMA and persistent effects on plus maze and brain serotonin content were similar in males and females. In contrast, females exhibited markedly greater locomotor stimulation after acute MDMA and also showed sensitization to an acute challenge 2 weeks later.

Conclusions MDMA elicits substantially greater locomotor activation in female rats than in males, but persistent effects on anxiety and serotonin content were similar in males and females.

Keywords MDMA · Anxiety · Sex differences - Serotonin · Locomotor activity Temperature

\section{Introduction}

3,4-Methylenedioxymethamphetamine (MDMA) elicits a unique behavioral profile that includes both pleasant and unpleasant physiological and psychological changes. MDMA increases heart rate, blood pressure, and body temperature, and influences learning and memory, anxiety, feelings of closeness, and hostility (Kalant 2001). MDMA causes a carrier-mediated release of 5-HT that at high doses produces an acute depletion at 4-6 h, with recovery by $24 \mathrm{~h}$ (Schmidt 1987). High-dose MDMA treatment in animals also causes a second, more long-lasting impairment of 5 -HT systems. This second phase is characterized by decreases in 5-HT and 5-hydroxyindoleacetic acid (5-HIAA), tryptophan hydroxylase activity, and the density of 5-HT reuptake sites (see review by Lyles and Cadet 2003). Although the patterns of exposure are quite different in rodent exposure models and typical human use and mediating mechanisms might be different, similar MDMAinduced decrements in 5-HT systems are reported in heavy MDMA users, including decreased concentrations of 5-HT 
and 5-HIAA in cerebrospinal fluid (McCann et al. 1994) and a decrease in the number of 5-HT transporter binding (Buchert et al. 2004; De Win et al. 2004; Ricaurte et al. 2000; Semple et al. 1999).

Heavy MDMA use affects both mood and cognition in humans (Gouzoulis-Mayfrank et al. 2000; McCardle et al. 2004; Montoya et al. 2002; Morgan 2000; Verdejo-Garcia et al. 2005). Some human MDMA users have also reported increased levels of anxiety that can persist even after periods of abstinence from the drug (Gamma et al. 2000; Parrott 2000; Verkes et al. 2001; Wareing et al. 2000). Animals treated with brief, high-dose regimens also exhibit persistent increases in anxiety-like behaviors, even without long-term serotonin depletion (Clemens et al. 2004; Fone et al. 2002; Gurtman et al. 2002; McGregor et al. 2003).

Few studies have investigated sex differences in MDMA effects. Women report greater subjective effects of the drug, including greater thought disturbances, perceptual changes, and fear of loss of body control (Liechti et al. 2001) and more midweek low after weekend use (Verheyden et al. 2002). In contrast, men experience greater increases in blood pressure (Liechti et al. 2001). Sex differences in the persevering effects of MDMA are more poorly understood, although greater reductions in the density of 5-HT transporters and the levels of 5-HIAA in women have been reported (Buchert et al. 2004; De Win et al. 2004; McCann et al. 1994). Although these reports suggest that the effects of MDMA are not equivalent in men and women, a number of factors affect this conclusion. The doses ingested by men and women may be different. In addition, there is often a high rate of polydrug use that may differ in men and women. Finally, preexisting differences in both serotonergic function and cognitive and emotional function may confound interpretation of the results.

Animal studies of sex differences in MDMA effects are even sparser. Fitzgerald et al. (1989) showed a higher level of MDMA, but not the metabolite MDA, in the plasma of female rats after a single drug injection, whereas Chu et al. (1996) reported lower brain concentrations of MDA, but not MDMA, in female rats after MDMA. Two recent behavioral studies report that females show enhanced locomotion, less startle response, and comparable effects in the plus maze (Bubenikova et al. 2005; Pelenicek et al. 2005).

The current study investigated sex differences in the effects of acute and repeated MDMA administration to rodents. Ear temperature and locomotor activity were determined after acute MDMA treatment. Locomotor activity, behavior in the elevated plus maze, and regional content of 5-HT and 5-HIAA were determined 2 weeks after the last treatment. These measures were selected because they are both sensitive and highly relevant to persistent adverse effects in human populations.

\section{Materials and methods}

Animals Adult male and female Sprague-Dawley rats (Charles River Laboratories, Raleigh, NC, USA) arrived at 60 days of age at least 1 week prior to testing. At the age of testing, rats were young adults (Spear 2000). Rats were housed three per cage under a 12:12 light-dark cycle with lights on at 6:00 a.m. in a controlled temperature and humidity environment. Food and water were available ad libitum. Animal care was in accordance with the principles of laboratory animal care as detailed in the Guide for the Care and Use of Laboratory Animals (NIH publication 865-23, Bethesda, MD, USA) and approved by the Institutional Animal Care and Use Committee. Female rats were used without regard to estrous cycle. Since the original treatment involved multiple days, it would have been impossible to conduct all aspects of the study at defined points in the estrous cycle.

Drug administration ( \pm ) 3,4-Methylenedioxymethamphetamine was provided by the National Institute on Drug Abuse (Rockville, MD). ( \pm ) MDMA was dissolved in $0.9 \%$ saline and delivered intraperitoneally in $1 \mathrm{ml} / \mathrm{kg}$. Animals received either saline or $15 \mathrm{mg} / \mathrm{kg}$ MDMA. Injections were delivered every $12 \mathrm{~h}$ (approximately 9 a.m. and 9 p.m.) for a total of eight injections over 4 consecutive days. This protocol was chosen because it produces persistent deficits in serotonin and changes in anxiety-like behaviors in adult rats (Lyles and Cadet 2003).

Experimental procedure Separate cohorts of animals were used to determine MDMA effects on body temperature, locomotion, and anxiety. Temperature and locomotor activity were monitored immediately following the morning injection of MDMA on days 1 and 4. Rats from all cohorts were singly housed during drug treatment to reduce hyperthermia (Dr. George Ricaurte, personal communication). Two weeks after the start of drug administration, behavioral testing on the elevated plus maze was performed. These rats were killed on day 18 for measurement of 5-HT and 5-HIAA content. All procedures were conducted in the same animal suite that was kept at an ambient temperature of $23-24^{\circ} \mathrm{C}$ for all experiments.

Temperature Ear temperature was measured using an Instant Ear Thermometer (Vet-Temp, Inc., San Diego, CA, USA) inserted slightly into the ear canal. Temperature was recorded directly before drug administration and 1, 2, and $3 \mathrm{~h}$ after treatment. Saline-treated male and female rats served as controls in this experiment. This device, although not as precise as an implanted probe, measures temperature to within $0.03^{\circ} \mathrm{C}$. A pilot study showed that rectal and ear 
probes yield comparable results for both basal and MDMAinduced increases.

Locomotor activity Activity experiments were performed in photocell devices (San Diego Instruments, Inc., San Diego, CA, USA). Interruptions of photobeams spaced $2.5 \mathrm{~cm}$ apart were recorded at 5-min intervals. Horizontal activity is reported as distance traveled in centimeters, and vertical activity is reported as the number of interruptions of rearing photobeams. Animals were placed in the chambers for a 30-min habituation period, then injected with saline or MDMA as described above. Locomotor activity was monitored for $5 \mathrm{~h}$ after the injection.

Elevated plus maze The elevated plus maze consisted of two open arms $(60 \mathrm{~cm} \times 9 \mathrm{~cm})$ and two perpendicular closed arms $(60 \mathrm{~cm} \times 9 \mathrm{~cm})$, forming a "plus" with a center square $(9 \mathrm{~cm} \times 9 \mathrm{~cm}) 60 \mathrm{~cm}$ off the ground. The closed arms had a $50-\mathrm{cm}$ wall. Open arms had a $1-\mathrm{cm}$ edge. Each rat was placed in an open field arena identical to the one used for locomotor testing for $5 \mathrm{~min}$ directly before plus maze testing to increase activity on the elevated plus maze and to enhance the likelihood of detecting both anxiogenic- and anxiolytic-like drug effects (Pellow and File 1986; Pellow et al. 1985). Each rat was then placed in the center of the plus maze, with its head facing an open arm in the direction opposite the experimenter. An experimenter recorded the number of open and closed arm entries, time spent on the open and closed arms, and the time spent in the center square for $5 \mathrm{~min}$. An entry onto an arm was recorded when both the forepaws and hindpaws of the rat were placed in the arm. Data are shown as percentage of open arm entries and percentage of time on the open arm (time on open arm / total time on open and closed arm $\times 100$ ). The apparatus was cleaned between rats.

Determination of brain 5-HTand 5-HIAA concentration Rats were killed 18 days following the initiation of MDMA administration, and the striatum, hypothalamus, hippocampus, and cortex were collected and stored at $-80^{\circ} \mathrm{C}$ until assay. The concentration of 5-HT and 5-HIAA was determined by a slight modification of previously used high-performance liquid chromatography (HPLC) method (Bero and Kuhn 1987). Tissue samples were homogenized in $0.2 \mathrm{~N}$ PCA containing $0.5 \mathrm{mM}$ EDTA and $0.5 \mathrm{mM}$ sodium metabisulfite and centrifuged at $10,000 \times g$, and the supernatant was injected onto the HPLC. The sample is enriched on a C18 precolumn (mobile phase: $0.05 \mathrm{M}$ citrate, $0.05 \mathrm{M}$ dibasic sodium phosphate, $0.5 \mathrm{mM}$ EDTA at $\mathrm{pH} 3.5$ ) and eluted onto an analytical C18 column (same mobile phase with $4-8 \%$ acetonitrile). Samples were detected by electrochemical detection with detector potential set at $+0.55 \mathrm{mV}$ vs $\mathrm{Ag} / \mathrm{AgCl}$ reference electrode. Data were collected with a computer-based data collection system and quantitated with the use of internal standard and external standard curves.

Statistical analysis All data were analyzed using analysis of variance (ANOVA) with the $p$ value set at 0.05 for significant effects. Newman-Keuls post hoc analysis was performed on all significant effects. All statistical testing was completed using NCSS 2000 software (NCSS, Inc., Kaysville, UT, USA). The effect of MDMA on temperature was assessed with a $2(\operatorname{sex}) \times 2$ (treatment) ANOVA with treatment day and time after injection as repeated measures. The effect of MDMA on locomotor activity was determined by completing separate analyses for horizontal and vertical activity with a $2(\operatorname{sex}) \times 2$ (treatment: saline or MDMA) ANOVA with time after injection as a repeated measure. Changes in motor activity during the habituation period and following MDMA administration across days (1, 4, and 14) were assessed by three-way repeated-measures ANOVA with sex and treatment as the between-subjects variable and day as the within-subject variable. Subsequent ANOVAs for each sex were also performed. The effects of sex and MDMA treatment on the elevated plus maze performance were analyzed with a $2(\operatorname{sex}) \times 2$ (drug treatment) ANOVA on the time spent in the open arms and open arm entries. Similar ANOVA analysis determined the effects of sex and MDMA treatment on the levels of 5-HT and 5-HIAA as dependent variables (nanograms per milligram wet tissue weight) for each brain region.

\section{Results}

Acute effects of MDMA

Figure 1a shows that MDMA administration on day 1 increased ear temperature similarly in both male and female rats. Repeated-measures ANOVA indicated a significant main effect of treatment $[F(1,28)=13.1, p<.001]$ and an effect of time after administration $[F(3,84)=4.66, p<.005$ and $F(3,84)=6.91, p<.001]$ for an interaction of treatment $\times$ time. There was no main effect of, or interaction with, sex. Figure $1 \mathrm{~b}$ shows the time course of temperature changes on day 4 (following the seventh of eight treatments). MDMA did not affect ear temperature on day 4 , indicating that both sexes became tolerant to the MDMA-induced hyperthermia across days of administration.

Figure 2a shows that horizontal activity increased following MDMA administration in both male and female rats. Activity increased significantly more in females than in males $[F(1,32)=19.78, p<.001$ for effect of sex; $F(1,32)=238.9$, $p<.001$ for effect of treatment; $F(1,32)=15.5, p<.001$ for 

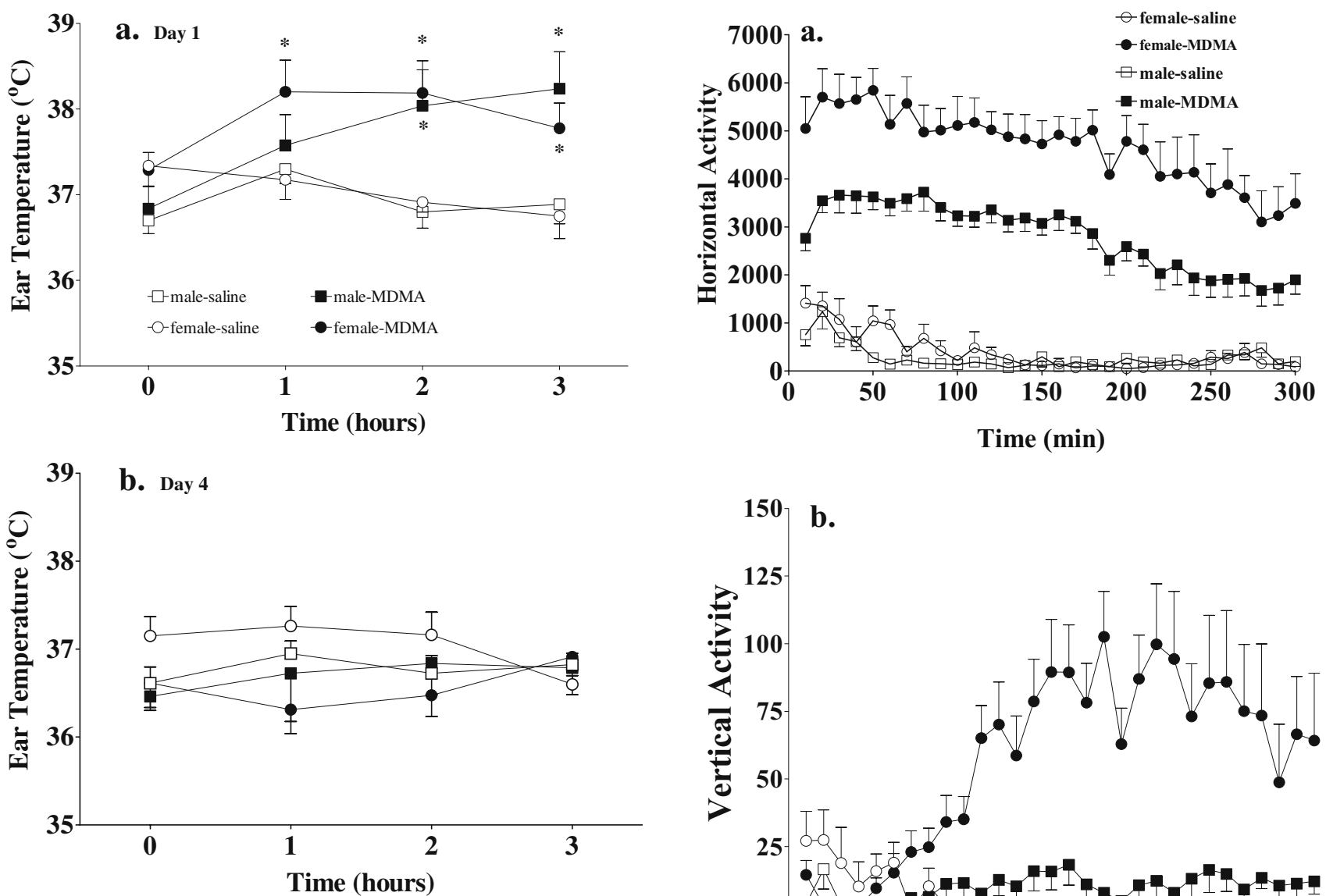

Fig. 1 The effect of MDMA or vehicle on ear temperature of male and female rats ( $n=8$ per group). Saline or $15 \mathrm{mg} / \mathrm{kg}$ MDMA was injected ip after recording the baseline temperature at time 0 on days 1 (a) and 4 (b) of treatment. MDMA increased ear temperature in male and female rats on day 1 but not day 4 . The symbol legend applies to both panels. Mean \pm SEM is shown in this and all figures. *Significantly different than time- and sex-matched saline controls $(p<.05)$

interaction of sex $\times$ treatment; $F(29,928)=11.4, p<.001$ for effect of time; $F(29,928)=5.67, p<.001$ for interaction of treatment $\times$ time]. Figure $2 \mathrm{~b}$ shows that MDMA also caused marked sex differences in rearing activity. MDMA induced a delayed but marked incidence of rearing in females but only modest increases in males $[F(1,32)=19.15, p<.001$ for an effect of sex; $F(1,32)=26.33, p<.001$ for an effect of treatment; $F(1,32)=13.97, p<.001$ for interaction of treatment $\times$ sex; $F(29,928)=4.10, p<.001$ for an effect of time; $F(29,928)=2.78, p<.001$ for interaction of sex $\times$ time; $F(29$, $928)=9.99, p<.001$ for interaction of treatment $\times$ time; and $F(29,928)=5.48, p<.001$ for sex $\times$ treatment $\times$ time $].$

Figure 3 shows horizontal locomotor behavior (a) during habituation on days 1,4 , and 14 and vertical activity (b) during habituation. Females were more active than males overall $[F(1,32)=31.3, p<.001$ for an effect of sex on horizontal activity and $F(1,32)=43.3, p<.001$ for vertical activity]. Both sex and treatment affected the horizontal activity during habituation as indicated by the significant interaction of sex $\times$ treatment $\times$ day $[F(2,64)=6.93$,

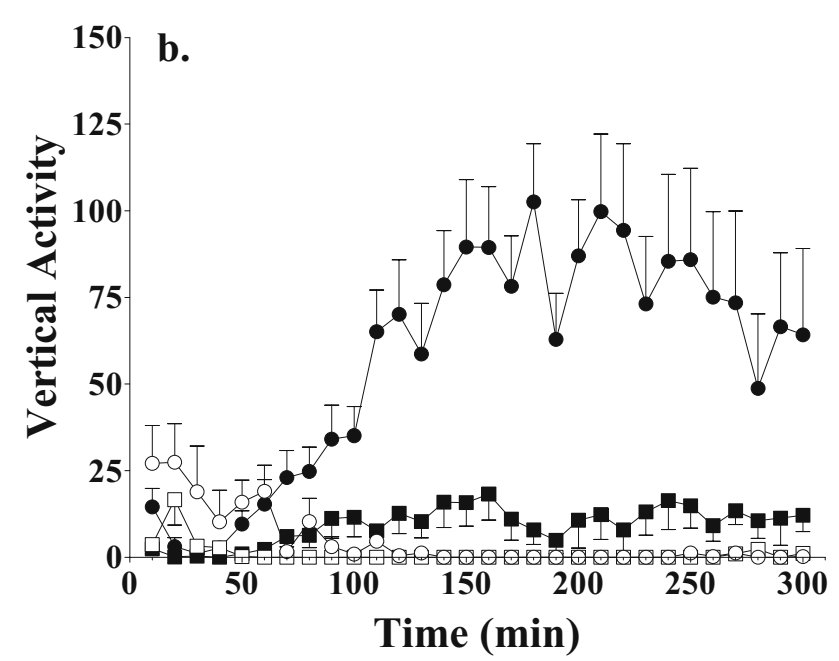

Fig. 2 The effect of acute MDMA or vehicle on motor behavior of male and female rats ( $n=9$ per group). The time courses of horizontal (a) and vertical activity (b) on day 1 are shown in 10-min intervals. MDMA administration increased motor behavior more in female rats

$p<.002]$. Subsequent analyses for each sex showed that horizontal locomotion during habituation changed across days in MDMA-treated females only. Activity in MDMAtreated females decreased during habituation on day 4 relative to day $1[F(2,32)=14.48, p<.001]$ for treatment $\times$ day interaction for females. Rearing during habituation changed in both MDMA-treated males and females $[F(2,64)=6.34, p<.003$ for treatment $\times$ day $]$, and there was a significant interaction of sex $\times$ treatment $\times$ day $[F(2$, $64)=3.98, p<.02]$. A significant interaction of treatment $x$ day was found in females $[F(2,32)=5.16, p<.01]$. Rearing decreased on both days 4 and 14 relative to day 1 in MDMA-treated males $[F(2,32)=5.15, p<.011$ for treatment $\times$ day in males alone].

The locomotor response to $15 \mathrm{mg} / \mathrm{kg}$ MDMA on day 1 (at the start of treatment), day 4 (at the end of treatment), and on day 14 (after 10 days of recovery) is shown in Fig. 4. Responses to saline treatment were small and did not change across days, and they are not shown to 

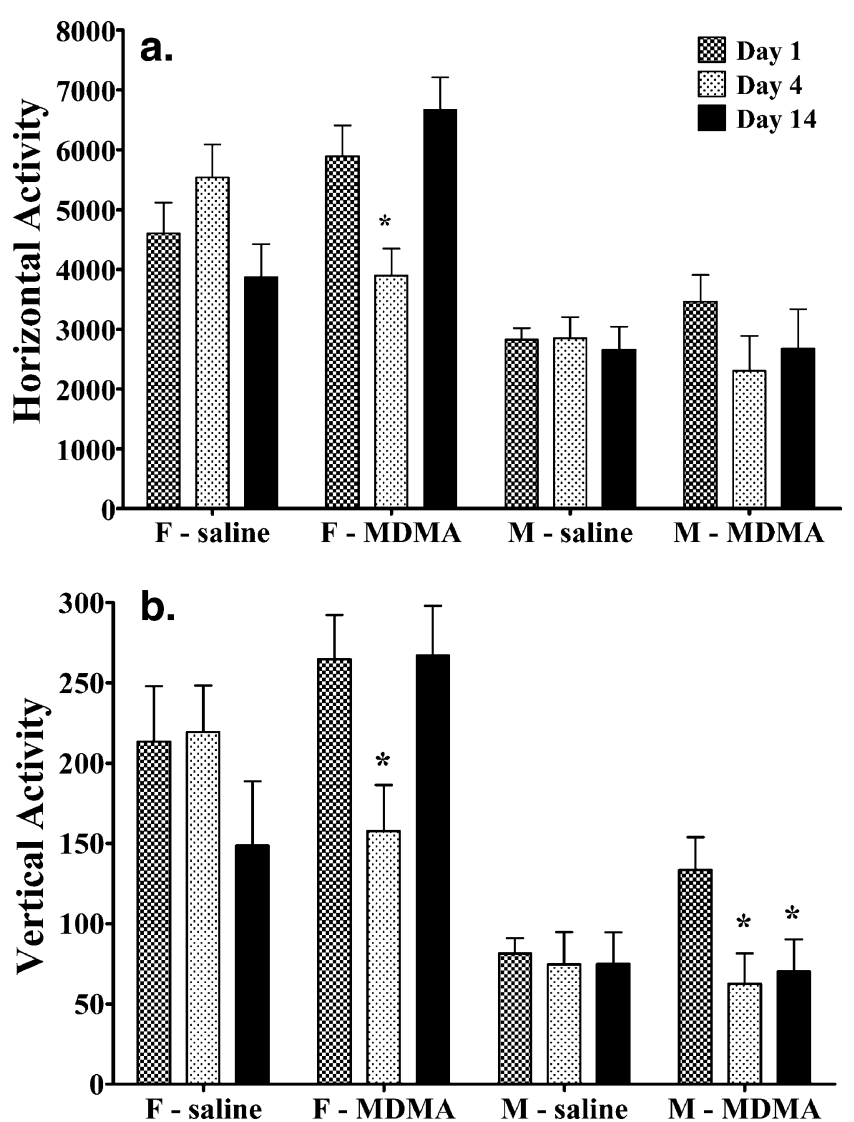

Fig. 3 Horizontal (a) and vertical (b) motor activity during habituation on treatment days 1,4 , and 14 ( $n=9$ per group). Habituation data on day 1 preceded initiation of MDMA treatment (days 1-4). Bar heights depict summed activity over the $60 \mathrm{~min}$ of habituation. MDMA treatment decreased horizontal activity in females and vertical activity in both males and females on day $4 .{ }^{*}$ Significantly different than day 1 data of the same sex and treatment $(p<.05)$

simplify graphic representation of the significant findings. Overall, the horizontal locomotor response (a) to MDMA changed over days $[F(2,32)=15.1, p<.001]$, and there was a significant sex difference $[F(1,16)=24.7, p<.001]$. Whereas the locomotor response in males was similar across days $(p=0.11)$, it changed in females $[F(2,8)=$ $13.45, p<.003]$ for an effect of day. Post hoc analysis indicated that the locomotor response to MDMA on day 14 was significantly greater than on days 1 or 4 in females $(p<0.05)$. Vertical activity exhibited a similar pattern (b). A significant sex difference in vertical activity was observed $[F(1,16)=25.1, p<.001]$. Because of the larger variance in this measure, the change over days was not statistically significant in females.

\section{Long-term effects of MDMA}

Figure 5a,b shows that MDMA treatment reduced the time spent in the open arms and in the number of open arm entries in male and female rats treated with MDMA 2 weeks
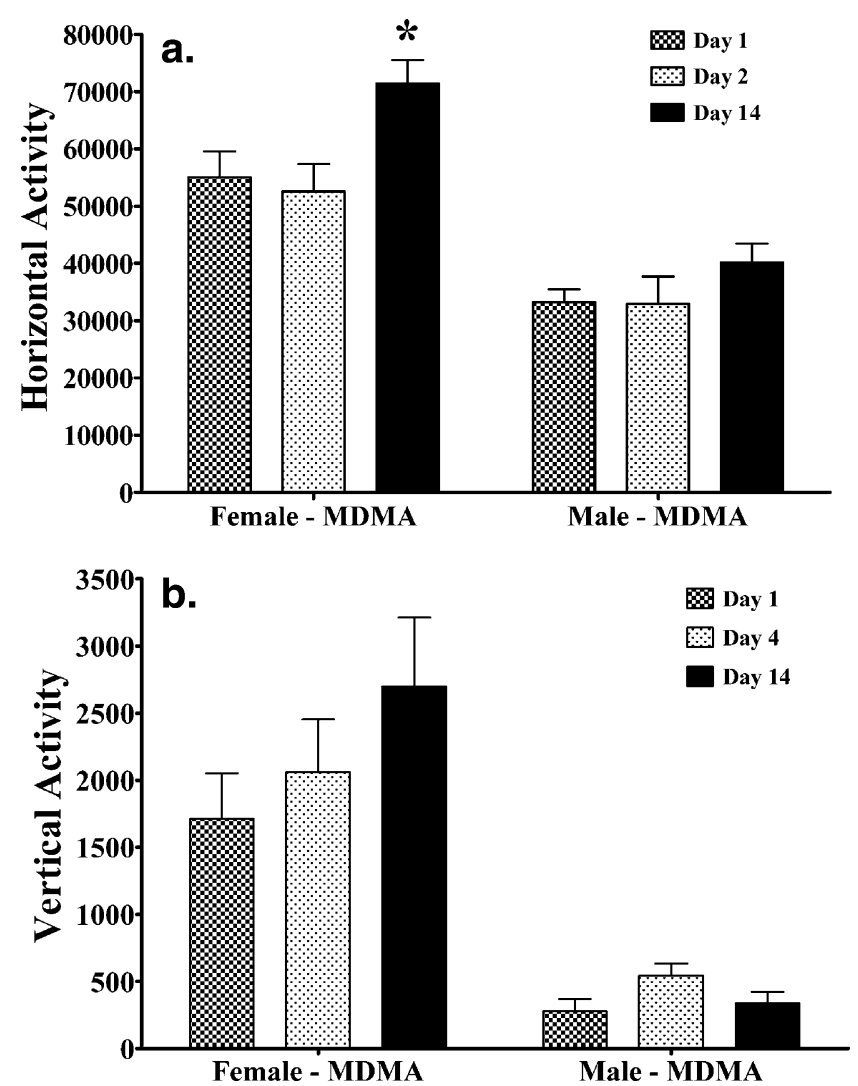

Fig. 4 Horizontal (a) and vertical (b) motor activity after MDMA $(15 \mathrm{mg} / \mathrm{kg}$ ) on treatment days 1,4 , and 14 ( $n=9$ per group). Bar heights depict summed activity over the $5 \mathrm{~h}$ after challenge. Horizontal activity increased in females on day 14 relative to days 1 and $4 .{ }^{*}$ Significantly different than females on days 1 and $4(p<.05)$

prior. ANOVA revealed a significant main effect of treatment on time spent in the open arms $[F(1,113)=$ $45.51, p<.001]$ and number of open arm entries $[F(1,113)=$ $18.07, p<.001]$. There was no significant main effect of sex, and no interaction with treatment. This reduction was not due to decreased locomotor activity, as there was no effect of treatment on the activity measure of total number of arm entries (data not shown).

MDMA treatment produced significant and comparable decreases in the levels of 5-HT and 5-HIAA in the hippocampus, striatum, hypothalamus, and cortex of male and female rats (see Fig. 6a-h). ANOVA revealed a significant main effect of treatment on the level of 5-HT in the striatum $[F(1,45)=23.31, p<.001]$, hypothalamus $[F(1,43)=20.35, p<.001]$, hippocampus $[F(1,45)=121.02$, $p<.001]$, and cortex $[F(1,45)=192.09, p<.001]$. A similar reduction in 5-HIAA was observed in the striatum $[F(1,45)=69.39, p<.001]$, hypothalamus $[F(1,43)=34.21$, $p<.001]$, hippocampus $[F(1,45)=120.77, p<.001]$, and cortex $[F(1,45)=264.94, p<.001]$. There was neither a main effect of sex nor a sex by treatment interaction in any brain areas for 5-HT or 5-HIAA. 

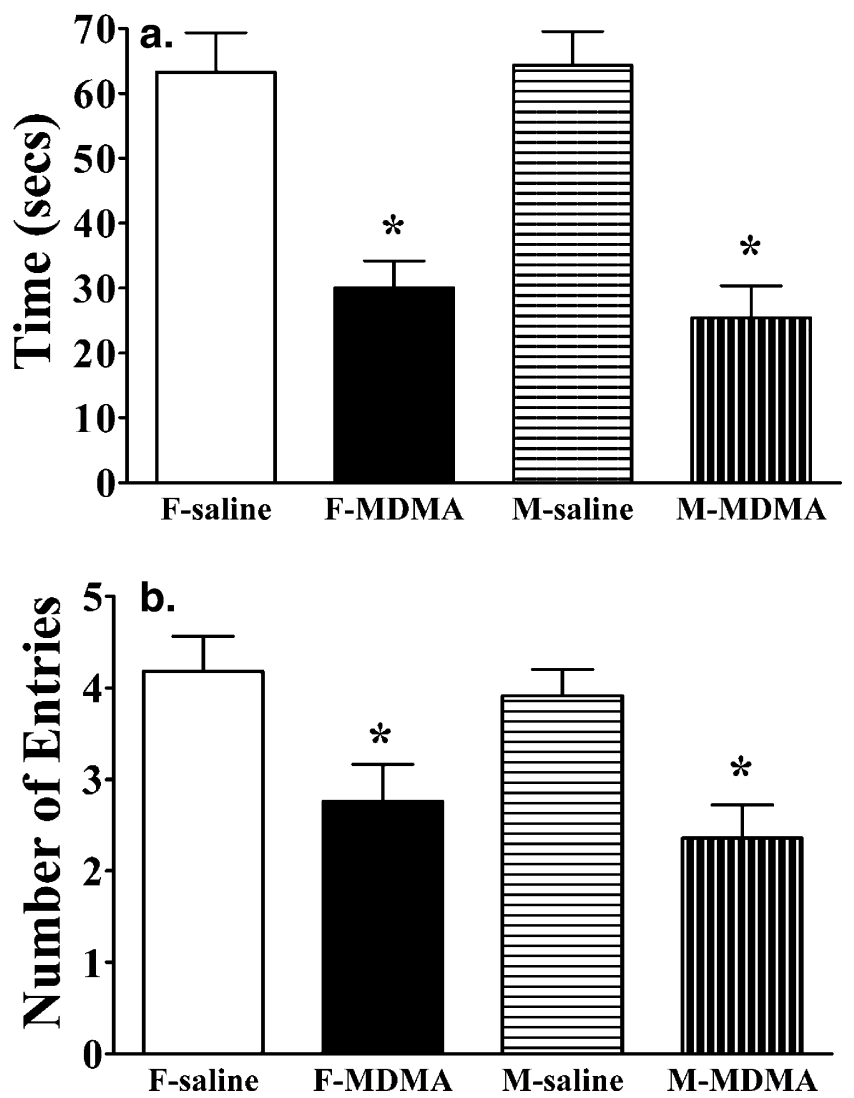

Fig. 5 Persistent effects of repeated MDMA or vehicle on open arm time (a) and the number of open arm entries (b) in the elevated plus maze. MDMA produced an anxiogenic effect in male and female rats in the elevated plus maze when tested 2 weeks following a 4-day, bid, dosing regimen $\left(n=28-35\right.$ per group). ${ }^{*}$ Significantly different than same-sex control rats $(p<0.05)$

\section{Discussion}

This study reports that rats exhibit sex specificity in MDMA locomotor effects, but not in other acute effects, or in enduring neurochemical or behavioral effects. Female rats showed remarkably greater behavioral activation than males after MDMA treatment initially and upon challenge after a 2-week recovery period. MDMA caused a modest and comparable elevation in temperature in both males and females. The depletions of 5-HT and 5-HIAA and increased time spent in the closed arms of the plus maze 2 weeks after the last treatment also were similar in males and females.

The markedly greater locomotor response to MDMA observed in females is consistent with the enhanced response of female rats to many psychomotor stimulants including cocaine and amphetamine (Becker et al. 1982; Festa and Quinones-Jenab 2004; Walker et al. 2001). Two recent reports of increased locomotor responses to MDMA in females relative to males and in ovariectomized females following estrogen treatment are consistent with the present report (Pelenicek et al. 2005; Zhou et al. 2003). The latter study supports a role for ovarian hormones in this augmented response. In the present study, enhanced responses were observed even though females were used irrespective of estrous cycle stage: it is likely that responses of females during high-estrogen phases of the cycle are even higher than the mean response that we recorded. The largest stimulant responses in female rats are typically observed during high-estrogen phases of the cycle (Walker et al. 2002), but significantly greater responses than males are observed even when females are used irrespective of cycle (Quinones-Jenab et al. 1999; Sell et al. 2000; Walker et al. 2001). A recent report of enhanced locomotor responses in prepubertal male rats relative to females may well reflect that lack of ovarian steroid enhancement in prepubertal females (Koenig et al. 2005).

The mechanism by which MDMA increases locomotor activity more in females is likely due to gonadal steroid effects on the dopaminergic and serotonergic mechanisms through which MDMA acts. MDMA releases dopamine both directly and indirectly through 5-HT release (Callaway et al. 1990; Koch and Galloway 1997; Schmidt et al. 1992; Yamamoto and Spanos 1988). Both 5-HT $1 \mathrm{~B}$ and 5-HT receptors can influence the MDMA locomotor response, although both stimulatory and inhibitory effects have been reported (Bankson and Cunningham 2002; Kehne et al. 1996; McCreary et al. 1999; Schmidt et al. 1992). Estrogen enhances basal, stimulated, and stimulant-induced dopamine release as well as both dopamine and serotonin receptors (see reviews by Becker 1999; Cyr et al. 2002).

The sex difference in locomotor activation is not likely caused by a difference in the pharmacokinetics of MDMA. Previous studies in rodents have shown that male and female rats have comparable brain levels of MDMA after acute treatment (Chu et al. 1996). In the present study, the acute hyperthermic effects of MDMA as well as the persevering effects on both serotonin and anxiety were comparable in males and females. Similar results of comparable 5-HT depletion in males and females were also reported by Slikker et al. (1989). If the effects reflected pharmacokinetic differences, then sex differences would have been expected in all of these measures.

The hyperthermic but not the locomotor effects of MDMA attenuated over the 4 days of treatment in both males and females. The temperature results agree with previous observations that MDMA increases body temperature (Colado et al. 1993; Dafters 1994; Mechan et al. 2001) and that this response diminishes across repeated days of administration (Cassel et al. 2004; Marston et al. 1999; Slikker et al. 1989). Locomotor activity has been reported to decrease or not change after comparable regimens (Cassel et al. 2004; Marston et al. 1999; Slikker et al. 1989). Effects on locomotion likely reflect the specific dose regimen. Attenuation could be expected with 
Fig. 6 Tissue content of serotonin (5-HT) and its metabolite, 5-HIAA, in rat brain areas. Administration of MDMA for 4 days produced significant depletions in the levels of 5-HT and 5-HIAA in the hippocampus, striatum, hypothalamus, and cortex of male and female rats 2 weeks following treatment ( $n=11-15$ per group). Panels on the left side show 5-HT (nanograms per milligram tissue) and on the right, 5-HIAA (nanograms per milligram tissue). *Significantly different than same-sex control rats $(p<.05)$
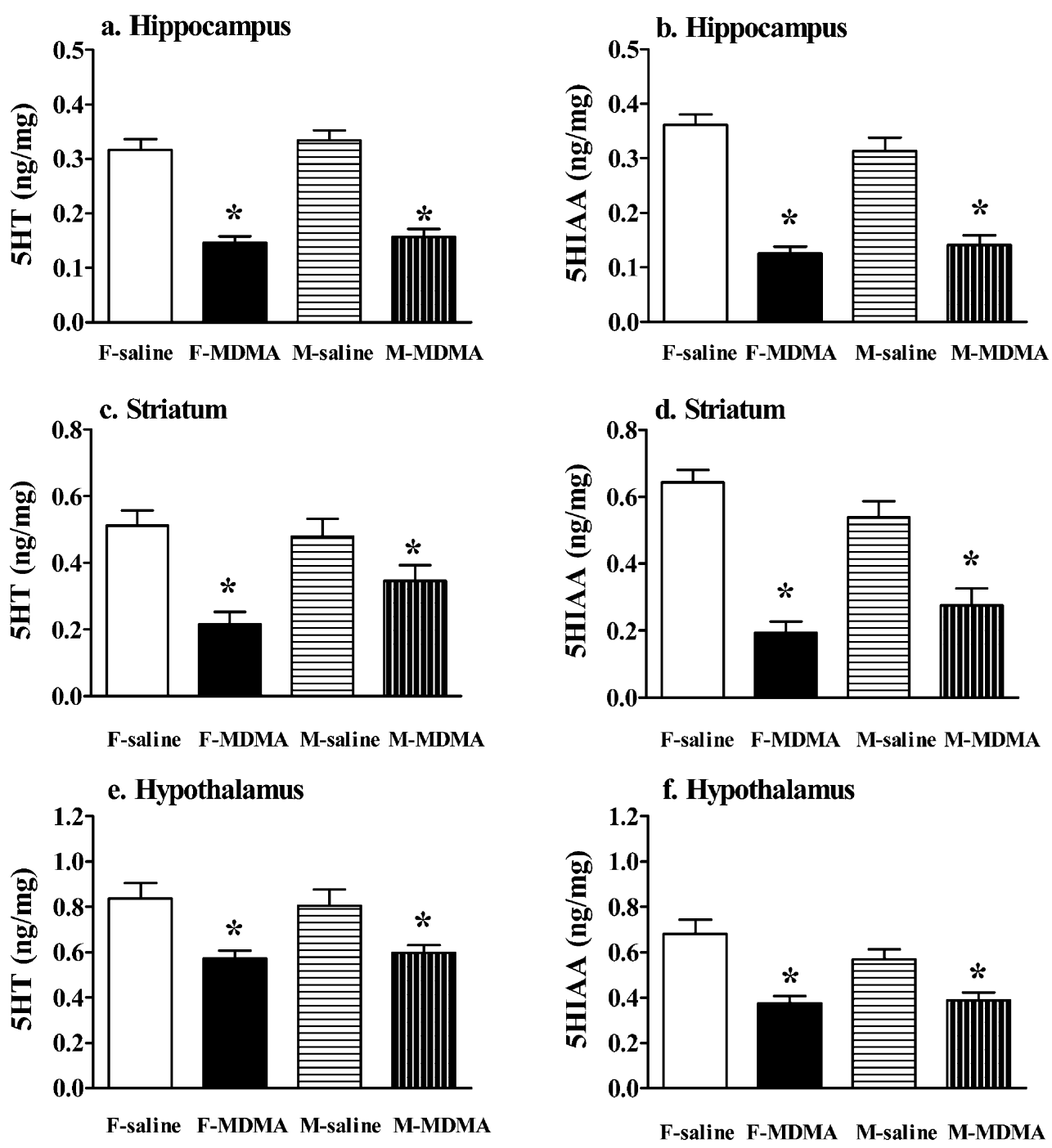

g. Cortex

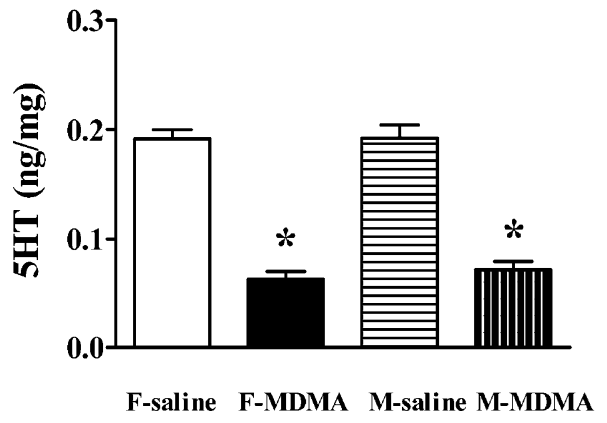

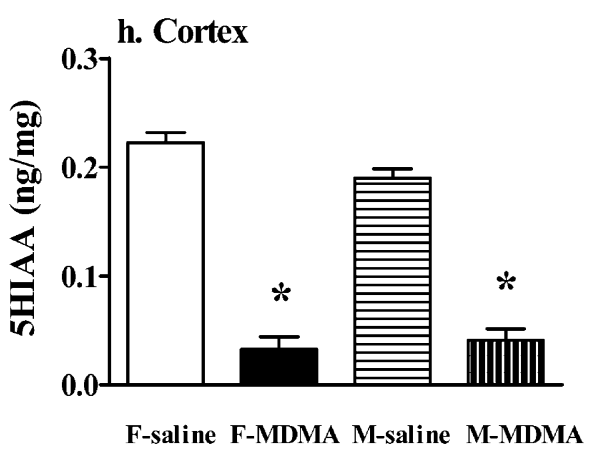

the present regimen since MDMA treatment transiently depletes 5-HT and presumably causes a successively smaller release of 5-HT (due to depleted pools) (Fuller 1978, 1985). Marked serotonin depletion can actually enhance locomotion in an open field or after stimulant challenge, but this has been observed only after more severe serotonin depletions than probably occurred in this study (Dringenberg et al. 1995; Gately et al. 1985). The present study utilized large MDMA challenge doses, and so a robust effect on locomotor stimulation might have offset diminished serotonin stores, although the latter were not quantitated at 4 days. Since the duration of treatment was so brief, this finding is not necessarily relevant to reports of gradual tolerance to the subjective effects of MDMA nor to reports of supersensitivity which occurs after longer treatment durations (Parrot 2005). 
Females but not males showed sensitized responding when tested 2 weeks after the last treatment. Several investigators reported sensitization in males (Dafters 1995; Kalivas et al. 1998; Spanos and Yamamoto 1989). However, sensitization in males following the brief 4-day paradigm used in this study has not been reported. The sensitization observed in females is consistent with the greater sensitization in females noted after repeated treatment with psychomotor stimulants like cocaine (Booze et al. 1999; Hu and Becker 2003; Sircar and Kim 1999). Multiple mechanisms could contribute to this enhanced response including greater changes in dopamine signaling, upregulation of serotonin receptors like that occurring after other manipulations that deplete serotonin, or some adaptation that is specific for MDMA (Dringenberg et al. 1995; Gately et al. 1985; Nestler 2004). The augmented response in females could reflect a sex-specific receptor upregulation facilitated by estrogen-facilitated $5-\mathrm{HT}_{2}$ receptor synthesis (Bankson and Cunningham 2002; Cyr et al. 2002; Reneman et al. 2000).

Are findings of enhanced locomotor activation and sensitization in females relevant to human experience with MDMA? Female MDMA users do report greater subjective (and aversive) effects of acute MDMA and greater midweek letdown after use when they receive doses comparable to males (Liechti et al. 2001; Topp et al. 1999; Verheyden et al. 2002). However, such studies are complicated by sex differences in preexisting psychiatric disorders as well as polydrug abuse that is typical for MDMA users (Milani et al. 2004). Our findings support the possibility that reported sex differences represent at least in part a greater pharmacologic action of the drug.

The MDMA treatment paradigm used in this study produced a sustained decrease in 5-HT and 5-HIAA in all brain regions studied that could reflect damage to serotonin nerve terminals. Most studies using comparable treatment regimens also report sustained reduction in serotonin content and other markers of serotonin nerve terminals (see review by Lyles and Cadet 2003). The extent to which these changes reverse is controversial: some studies show restoration of serotonin content in rodents after extremely long recovery times (Battaglia et al. 1988; Lew et al. 1996; Sabol et al. 1996; Scanzello et al. 1993), and some assert that nerve terminals are not damaged (Wang et al. 2005). The loss of serotonin in the present study occurred with only modest temperature increases. Elevated temperature exacerbates the serotonin loss after MDMA (Colado et al. 1993; Malberg and Seiden 1998), but loss can occur without markedly elevated temperatures (McGregor et al. 2003). The present results suggest that "harm reduction" approaches by limiting hyperthermia are not a guarantee against serotonin depletion.
The relevance of the present findings to prediction of human risk from MDMA use is controversial. The purpose of the present study was to produce robust depletions in order to evaluate the long-term behavioral consequences for those heavy users who do experience serotonin depletion rather than model typical human use patterns. An emerging literature in humans and animals does suggest that humans who are heavy MDMA users experience measurable loss of serotonergic markers (Buchert et al. 2004; De Win et al. 2004; Ricaurte et al. 2000; Semple et al. 1999), although recovery in these markers may occur (Buchert et al. 2004; De Win et al. 2004) and the mediating mechanisms are still unknown.

The increase in anxiety-like behavior in the plus maze observed 2 weeks after the end of treatment suggests that diminished serotonergic function might contribute to this behavioral consequence. Similar behavioral changes after serotonin-depleting MDMA regimens have been reported previously in MDMA-treated rats (Clemens et al. 2004; Gurtman et al. 2002; McGregor et al. 2003; Morley et al. 2001). However, the regulation of mood by 5 -HT is complicated. Although 5-HT depletion after the serotonin neurotoxin 5,7-DHT can decrease anxiety-like behaviors (Briley et al. 1990), others have shown no effect (Critchley et al. 1992) or increases in such behaviors after serotonin depletion (Balfour et al. 1986). Hall et al. (1999) observed a decrease in open arm time on the elevated plus maze following moderate 5-HT depletion and no effect following extreme 5-HT depletion. These authors propose that the effects of mild to moderate 5-HT lesions reflect compensatory changes (increases) in basal extracellular levels of 5-HT rather than the loss of 5-HT neurons. The anatomical location of the 5-HT depletion may also be a critical variable. The dorsal raphe nucleus may be important in behaviors on the elevated plus maze (File and Gonzalez 1996; Gonzalez and File 1997; Gonzalez et al. 1998). MDMA preferentially depletes 5-HT from fine-diameter neurons arising from the dorsal, but not median, raphe nucleus (Mamounas et al. 1991), suggesting that MDMA administration may lead to an anatomically specific pattern of 5-HT depletion and, subsequently, have specific effects on plus maze performance.

These findings in animal models suggest that reports of disturbed mood and increased anxiety in heavy human users could reflect impaired serotonergic function. Graeff et al. (1993) have suggested that the elevated plus maze is comparable to aspects of panic disorder in humans. The current observation of altered plus maze performance may be analogous to reports of the development of panic disorder at time points not directly associated with drug use (McCann and Ricaurte 1992; Windhaber et al. 1998; Whitaker-Azmitia and Aronson 1989). However, the mediating mechanisms for persistent anxiety-like behaviors 
after exposure to MDMA have not been established definitively in either rodents or humans. Given the different patterns of exposure in rodent models and after human use, the mediating mechanisms including the involvement of serotonin deficits might be different.

The reported consequences of even heavy MDMA use on mood in humans are highly variable. Studies of MDMA users report no effect, increases, or decreases in selfperceptions of anxiety (Liester et al. 1992; Morgan 1998; Parrott 2000; Verkes et al. 2001; Wareing et al. 2000). These diverse results suggest that MDMA influences on anxiety levels are likely dependent upon the total exposure to MDMA, the time of abstinence from the drug, use of other drugs, and the type of anxiety assessed.

The contrast between the marked sex difference in the acute locomotor activation and the absence of sex differences in the persistent effects of MDMA suggests that sex differences in the subjective response to drug intoxication may not predict its persistent consequences. Several clinical studies report greater loss of serotonin terminal markers in women than in men (Buchert et al. 2004; De Win et al. 2004; McCann et al. 1994). These differences in humans could reflect the average greater dose women ingest due to the fixed dose that most human users receive rather than a specific vulnerability to serotonin depletion in women.

In conclusion, the current study showed that MDMA elicited much more robust locomotor activation in female than in male rats, but caused similar serotonin depletion and persistent anxiety-like behaviors 2 weeks after the end of treatment. This study has several potential extrapolations to human MDMA users. First, the greater loss of serotonin transporters observed in women may reflect greater total drug exposure rather than a greater sensitivity to serotonin depletion. Second, the greater subjective effects that women report could reflect greater acute MDMA effects on dopaminergic and serotonergic function. One important final caveat in interpreting any animal model of MDMA exposure is that the exposure patterns do not mimic typical human exposure patterns. Therefore, it is important to extrapolate cautiously to predict risk in human populations.

Acknowledgments The authors would like to thank Dr. George Ricaurte and Branden Cord for their assistance.

\section{References}

Balfour DJ, Benwell ME, Graham CA, Vale AL (1986) Behavioural and adrenocortical responses to nicotine measured in rats with selective lesions of the 5-hydroxytryptaminergic fibres innervating the hippocampus. Br J Pharmacol 89:341-347

Bankson MG, Cunningham KA (2002) Pharmacological studies of the acute effects of (+)-3,4-methylenedioxymethamphetamine on locomotor activity: role of $5-\mathrm{HT}_{1 \mathrm{~b} / 1 \mathrm{~d}}$ and $5-\mathrm{HT}_{2}$ receptors. Neuropsychopharmacology 26:40-52
Battaglia G, Yeh SY, De Souza EB (1988) MDMA-induced neurotoxicity: parameters of degeneration and recovery of brain serotonin neurons. Pharmacol Biochem Behav 29:269-274

Becker JB (1999) Gender differences in dopaminergic function in striatum and nucleus accumbens. Pharmacol Biochem Behav 64:803-812

Becker JB, Robinson TE, Lorenz KA (1982) Sex differences and estrous cycle variations in amphetamine-elicited rotational behavior. Eur J Pharmacol 80:65-72

Bero LA, Kuhn CM (1987) Role of serotonin in opiate-induced prolactin secretion and antinociception in the developing rat. J Pharmacol Exp Ther 240:831-836

Booze RM, Welch MA, Wood ML, Billings KA, Apple SR, Mactutus CF (1999) Behavioral sensitization following repeated intravenous nicotine administration: gender differences and gonadal hormones. Pharmacol Biochem Behav 64:827-839

Briley M, Chopin P, Moret C (1990) Effect of serotonergic lesion on "anxious" behavior measured in the elevated plus-maze test in the rat. Psychopharmacology (Berl) 101:187-189

Bubenikova V, Votava M, Hoaracek J, Palenicek T (2005) Relation of sex and estrous phase to deficits in prepulse inhibition of the startle response induced by ecstasy (MDMA). Behav Pharmacol 16(2): $127-130$

Buchert R, Thomasius R, Wilke F, Petersen K, Nebeling B, Obrocki J, Schulze O, Schmidt U, Clausen M (2004) A voxel-based PET investigation of the long term effects of "Ecstasy" consumption on brain serotonin transporters. Am J Psychiatry 161:1181-1189

Callaway CW, Wing LL, Geyer MA (1990) Serotonin release contributes to the locomotor stimulant effects of 3,4-methylenedioxymethamphetamine in rats. J Pharmacol Exp Ther 254:456-464

Cassel JC, Jeltsch H, Koenig J, Jones BC (2004) Locomotor and pyretic effects of MDMA-ethanol associations in rats. Alcohol 34:285-289

Chu T, Kumagai Y, DiStefano EW, Cho AK (1996) Disposition of methylenedioxymethamphetamine and three metabolites in the brains of different rat strains and their possible roles in acute serotonin depletion. Biochem Pharmacol 51:789-796

Clemens KJ, van Nieuwenhuyzen PS, Li KM, Cornish JL, Hunt GE, McGregor IS (2004) MDMA ("ecstasy"), methamphetamine and their combination: long-term changes in social interaction and neurochemistry in the rat. Psychopharmacology (Berl) 173:318-325

Colado MI, Murray TK, Green AR (1993) 5-HT loss in rat brain following 3,4-methylenedioxymethamphetamine (MDMA), p-chloroamphetamine and fenfluramine administration and effects of chlormethiazole and dizocilpine. $\mathrm{Br} \mathrm{J}$ Pharmacol 108:583-589

Critchley MA, Njung'e K, Handley SL (1992) Actions and some interactions of 5-HT1A ligands in the elevated X-maze and effects of dorsal raphe lesions. Psychopharmacology (Berl) 106:484-490

Cyr M, Calon F, Morissette M, Di Paolo T (2002) Estrogenic modulation of brain activity: implications for schizophrenia and Parkinson's disease. J Psychiatry Neurosci 27(1):12-27

Dafters RI (1994) Effect of ambient temperature on hyperthermia and hyperkinesis induced by 3,4-methylenedioxymethamphetamine (MDMA or "ecstasy") in rats. Psychopharmacology (Berl) 114:505-508

Dafters RI (1995) Hyperthermia following MDMA administration in rats: effects of ambient temperature, water consumption, and chronic dosing. Physiol Behav 58:877-882

De Win MML, Reneman L, Reitsma JB, den Heeten GJ, Booij J, van den Brink W (2004) Mood disorders and serotonin transporter density in ecstasy users - the influence of long-term abstention, dose and gender. Psychopharmacology (Berl) 173:376-382

Dringenberg HC, Hargreaves EL, Baker GB, Cooley RK, Vanderwolf $\mathrm{CH}$ (1995) p-Chlorophenylalanine-induced serotonin depletion: reduction in exploratory locomotion but no obvious sensorymotor deficits. Behav Brain Res 68:229-237 
Festa ED, Quinones-Jenab V (2004) Gonadal hormones provide the biological basis for sex differences in behavioral responses to cocaine. Horm Behav 46:509-519

File SE, Gonzalez LE (1996) Anxiolytic effects in the plus-maze of $5-\mathrm{HT}_{\mathrm{A}}$-receptor ligands in dorsal raphe and ventral hippocampus. Pharmacol Biochem Behav 54:123-128

Fitzgerald RL, Blanke RV, Rosecrans JA, Glennon RA (1989) Stereochemistry of the metabolism of MDMA to MDA. Life Sci 45:295-301

Fone KC, Beckett SR, Topham IA, Swettenham J, Ball M, Maddocks L (2002) Long-term changes in social interaction and reward following repeated MDMA administration to adolescent rats without accompanying serotonergic neurotoxicity. Psychopharmacology (Berl) 159:437-444

Fuller RW (1978) Neurochemical effects of serotonin neurotoxins: an introduction. Ann N Y Acad Sci 305:178-181

Fuller RW (1985) Persistent effects of amphetamine, p-chloroamphetamine, and related compounds on central dopamine and serotonin neurons in rodents. Psychopharmacol Bull 21:528-532

Gamma A, Frei E, Lehmann D, Pascual-Marqui RD, Hell D, Vollenweider FX (2000) Mood state and brain electric activity in ecstasy users. Neuroreport 11:157-162

Gately PF, Poon SL, Segal DS, Geyer MA (1985) Depletion of brain serotonin by 5,7 dihydroxytryptamine alters the response to amphetamine and the habituation of locomotor activity in rats. Psychopharmacology (Berl) 87(4):400-405

Gonzalez LE, File SE (1997) A five minute experience in the elevated plus-maze alters the state of the benzodiazepine receptor in the dorsal raphe nucleus. J Neurosci 17:1505-1511

Gonzalez LE, Ouagazzal AM, File SE (1998) Stimulation of benzodiazepine receptors in the dorsal hippocampus and median raphe reveals differential GABAergic control in two animal tests of anxiety. Eur J Neurosci 10:3673-3680

Gouzoulis-Mayfrank E, Daumann J, Tuchtenhagen F, Pelz S, Becker S, Kunert HJ, Fimm B, Sass H (2000) Impaired cognitive performance in drug free users of recreational ecstasy (MDMA). J Neurol Neurosurg Psychiatry 68:719-725

Graeff FG, Silveira MC, Nogueira RL, Audi EA, Oliveira RM (1993) Role of the amygdala and periaqueductal gray in anxiety and panic. Behav Brain Res 58:123-131

Gurtman CG, Morley KC, Li KM, Hunt GE, McGregor IS (2002) Increased anxiety in rats after 3,4-methylenedioxymethamphetamine. Eur J Pharmacol 446:89-96

Hall FS, De Vries AC, Fong GW, Huang S, Pert A (1999) Effects of 5,7-dihydroxytryptamine depletion of tissue serotonin levels on extracellular serotonin in the striatum assessed with in vivo microdialysis: relationship to behavior. Synapse 33:16-25

Hu M, Becker JB (2003) Effects of sex and estrogen on behavioral sensitization to cocaine in rats. J Neurosci 23:693-699

Kalant H (2001) The pharmacology and toxicology of "ecstasy" (MDMA) and related drugs. CMAJ 165:917-928

Kalivas PW, Duffy P, White SR (1998) MDMA elicits behavioral and neurochemical sensitization in rats. Neuropsychopharmacology $18: 469-479$

Kehne JH, Ketteler HJ, McCloskey TC, Sullivan CK, Dudley MW, Schmidt CJ (1996) Effects of the selective 5-HT2 ${ }_{\mathrm{A}}$ receptor antagonist MDL 100,907 on MDMA-induced locomotor stimulation in rats. Neuropsychopharmacology 15:116-124

Koch S, Galloway MP (1997) MDMA induced dopamine release in vivo: role of endogenous serotonin. J Neural Trans 104:135-146

Koenig J, Lazarus C, Jeltsch H, Hamida SB, Riegert C, Kelche C, Jones BC, Cassel JC (2005) MDMA (ecstasy) effects in pubescent rats: males are more sensitive than females. Pharmacol Biochem Behav 81:635-644

Lew R, Sabol KE, Chou C, Vosmer GL, Richards J, Seiden LS (1996) Methylenedioxymethamphetamine-induced serotonin deficits are followed by partial recovery over a 52-week period. Part II: radioligand binding and autoradiography studies. J Pharmacol Exp Ther 276:855-865

Liechti ME, Gamma A, Vollenweider FX (2001) Gender differences in the subjective effects of MDMA. Psychopharmacology (Berl) 154:161-168

Liester MB, Grob CS, Bravo GL, Walsh RN (1992) Phenomenology and sequelae of 3,4-methylenedioxymethamphetamine use. J Nerv Ment Dis 180:345-352

Lyles J, Cadet JL (2003) Methylenedioxymethamphetamine (MDMA, Ecstasy) neurotoxicity: cellular and molecular mechanisms. Brain Res Rev 42:155-168

Malberg JE, Seiden LS (1998) Small changes in ambient temperature cause large changes in 3,4-methylenedioxymethamphetamine (MDMA)-induced serotonin neurotoxicity and core body temperature in the rat. J Neurosci 18:5086-5094

Mamounas LA, Mullen CA, O'Hearn E, Molliver ME (1991) Dual serotoninergic projections to forebrain in the rat: morphologically distinct 5-HT axon terminals exhibit differential vulnerability to neurotoxic amphetamine derivatives. J Comp Neurol 314: $558-586$

Marston HM, Reid ME, Lawrence JA, Olverman HJ, Butcher SP (1999) Behavioural analysis of the acute and chronic effects of MDMA treatment in the rat. Psychopharmacology (Berl) 144: $67-76$

McCardle K, Luebbers S, Carter JD, Croft RJ, Stough C (2004) Chronic MDMA (ecstasy) use, cognition and mood. Psychopharmacology (Berl) 173:434-439

McCann UD, Ricaurte GA (1992) MDMA ("ecstasy") and panic disorder: induction by a single dose. Biol Psychiatry 32: 950-953

McCann UD, Ridenour A, Shaham Y, Ricaurte GA (1994) Serotonin neurotoxicity after $( \pm)$ 3,4-methylenedioxymethamphetamine (MDMA; "Ecstasy"): a controlled study in humans. Neuropsychopharmacology 10:129-138

McCreary AC, Bankson MG, Cunningham KA (1999) Pharmacological studies of the acute and chronic effects of (+)-3, 4methylenedioxymethamphetamine on locomotor activity: role of 5-hydroxytryptamine $\left(1_{\mathrm{A}}\right)$ and 5-hydroxytryptamine $\left(1_{\mathrm{B}} / 1_{\mathrm{D}}\right)$ receptors. J Pharmacol Exp Ther 290:965-973

McGregor IS, Clemens KJ, Van der Plasse G, Li KM, Hunt GE, Chen F, Lawrence AJ (2003) Increased anxiety 3 months after brief exposure to MDMA ('Ecstasy') in rats: association with altered 5-HT transporter and receptor density. Neuropsychopharmacology $28: 1472-1484$

Mechan AO, O'Shea E, Elliot JM, Colado MI, Green AR (2001) A neurotoxic dose of 3,4-methylenedioxymethamphetamine (MDMA; ecstasy) to rats results in a long term defect in thermoregulation. Psychopharmacology (Berl) 155:413-418

Milani RM, Parott AC, Turner JJ, Fox HC (2004) Gender differences in self-reported anxiety, depression and somatization among ecstasy/MDMA polydrug users, alcohol/tobacco users and nondrug users. Addict Behav 29:965-971

Montoya AG, Sorrentino R, Lukas SE, Price BH (2002) Long-term neuropsychiatric consequences of "Ecstasy" (MDMA): a review. Harvard Rev Psychiatry 10:212-220

Morgan MJ (1998) Recreational use of "ecstasy" (MDMA) is associated with elevated impulsivity. Neuropsychopharmacology $19: 252-264$

Morgan MJ (2000) Ecstasy (MDMA): a review of its possible persistent psychological effects. Psychopharmacology (Berl) 152:230-248

Morley KC, Gallate JE, Hunt GE, Mallet PE, McGregor IS (2001) Increased anxiety and impaired memory in rats 3 months after administration of 3,4-methylenedioxymethamphetmaine ("Ecstasy"). Eur J Pharmacol 433:91-99 
Nestler EJ (2004) Molecular mechanisms of drug addiction. Neuropharmacology 47:24-32

Parrott AC (2000) Human research on MDMA (3,4-methylenedioxymethamphetamine) neurotoxicity: cognitive and behavioural indices of change. Neuropsychobiology 42:17-24

Parrot AC (2005) Chronic tolerance to recreational MDMA (3,4methylenedioxymethamphetamine) or Ecstasy. J Psychopharmacol 19:71-83

Pelenicek T, Votava M, Bubenikova V, Horacek J (2005) Increased sensitivity to the acute effects of MDMA ("ecstasy") in female rats. Physiol Behav 86:546-553

Pellow S, File SE (1986) Anxiolytic and anxiogenic drug effects on exploratory activity in an elevated plus-maze: a novel test of anxiety in the rat. Pharmacol Biochem Behav 24:525-529

Pellow S, Chopin P, File SE, Briley M (1985) Validation of open: closed arm entries in an elevated plus-maze as a measure of anxiety in the rat. J Neurosci Methods 14:149-167

Quinones-Jenab V, Ho A, Schlussman SD, Franck J, Kreek MJ (1999) Estrous cycle differences in cocaine-induced stereotypic and locomotor behaviors in Fischer rats. Behav Brain Res 101:15-20

Reneman L, Booij J, Schmand B, van den Brink W, Gunning B (2000) Memory disturbances in "Ecstasy" users are correlated with an altered brain serotonin neurotransmission. Psychopharmacology (Berl) 148:22-324

Ricaurte GA, McCann UD, Szabo Z, Scheffel U (2000) Toxicodynamics and long-term toxicity of the recreational drug, 3,4methylenedioxymethamphetamine (MDMA, 'Ecstasy'). Toxicol Lett 112-113:143-146

Sabol KE, Lew R, Richards JB, Vosmer GL, Seiden LS (1996) Methylenedioxymethamphetamine-induced serotonin deficits are followed by partial recovery over a 52-week period. Part I: synaptosomal uptake and tissue concentrations. J Pharmacol Exp Ther 276:846-854

Scanzello CR, Hatzidimitriou G, Martello AL, Katz JL, Ricaurte GA (1993) Serotonergic recovery after $( \pm) 3,4$-(methylenedioxy) methamphetamine injury: observations in rats. J Pharmacol Exp Ther 264:1484-1491

Schmidt CJ (1987) Neurotoxicity of the psychedelic amphetamine, methylenedioxymethamphetamine. J Pharmacol Exp Ther 240:1-7

Schmidt CJ, Black CK, Taylor VL, Fadayel GM, Humphreys TM, Nieduzak TR, Sorensen SM (1992) The 5-HT2 receptor antagonist, MDL 28,133A, disrupts the serotonergic-dopaminergic interaction mediating the neurochemical effects of 3,4-methylenedioxymethamphetamine. Eur J Pharmacol 220:151-159

Sell SL, Scalzitti JM, Thomas ML, Cunningham KA (2000) Influence of ovarian hormones and estrous cycle on the behavioral response to cocaine in female rats. J Pharmacol Exp Ther 293(3):879-886

Semple DM, Ebmeier KP, Glabus MF, O'Carroll RE, Johnstone EC (1999) Reduced in vivo binding to the serotonin transporter in the cerebral cortex of MDMA ('ecstasy') users. Br J Psychiatry 175:186-188, 63-69

Sircar R, Kim D (1999) Female gonadal hormones differentially modulate cocaine-induced behavioral sensitization in Fischer, Lewis and Sprague-Dawley rats. J Pharmacol Exp Ther 289:54-65
Slikker W Jr, Holson RR, Ali SF, Kolta MG, Paule MG, Scallet AC, McMillan DE, Bailey JR, Hong JS, Scalzo FM (1989) Behavioral and neurochemical effects of orally administered MDMA in the rodent and nonhuman primate. Neurotoxicology 10:529-542

Spanos LJ, Yamamoto BK (1989) Acute and subchronic effects of methylenedioxymethamphetamine $[( \pm)$ MDMA $]$ on locomotion and serotonin syndrome behavior in the rat. Pharmacol Biochem Behav 32:835-840

Spear LP (2000) The adolescent brain and age-related behavioral manifestations. Neurosci Biobehav Rev 24(4):417-463

Topp L, Hando J, Dillon P, Roche A, Solowij N (1999) Ecstasy use in Australia: patterns of use and associated harm. Drug Alcohol Depend 55:105-115

Verdejo-Garcia AJ, Lopez-Torrecillas F, Aguilar de Arcos F, PerezGarcia M (2005) Differential effects of MDMA, cocaine and cannabis use severity on distinctive component of the executive functions in polysubstance users: a multiple regression analysis. Addict Behav 30:89-101

Verheyden SL, Hadfield J, Calin T, Curran HV (2002) Sub-acute effects of MDMA ( \pm 3 ,4-methylenedioxymethamphetamine, "ecstasy") on mood: evidence of gender differences. Psychopharmacology (Berl) 161:23-31

Verkes RJ, Gijsman HJ, Pieters MS, Schoemaker RC, de Visser S, Kuijpers M, Pennings EJ, de Bruin D, Van de Wijngaart G, Van Gerven JM, Cohen AF (2001) Cognitive performance and serotonergic function in users of ecstasy. Psychopharmacology (Berl) 153:196-202

Walker QD, Cabassa J, Kaplan KA, Li ST, Haroon J, Spohr HA, Kuhn CM (2001) Sex differences in cocaine-stimulated motor behavior: disparate effects of gonadectomy. Neuropsychopharmacology 25:118-130

Walker QD, Nelson CJ, Smith D, Kuhn CM (2002) Vaginal lavage attenuates cocaine-stimulated activity and establishes place preference in rats. Pharmacol Biochem Behav 73:743-752

Wang X, Baumann MH, Xu H, Morales M, Rothman RB (2005) $( \pm)-3,4-$ Methylenedioxymethamphetamine administration to rats does not decrease levels of the serotonin transporter protein or alter its distribution between endosomes and the plasma membrane. J Pharmacol Exp Ther 314(3):1002-1012

Wareing M, Fisk JE, Murphy PN (2000) Working memory deficits in current and previous users of MDMA ('ecstasy'). Br J Psychol 91(Pt 2):181-188

Whitaker-Azmitia PM, Aronson TA (1989) "Ecstasy" (MDMA)induced panic. Am J Psychiatry 146:119

Windhaber J, Maierhofer D, Dantendorfer K (1998) Panic disorder induced by large doses of 3,4-methylenedioxymethamphetamine resolved by paroxetine. J Clin Psychopharmacol 18:95-96

Yamamoto BK, Spanos LJ (1988) The acute effects of methylenedioxymethamphetamine on dopamine release in the awakebehaving rat. Eur J Pharmacol 148:195-203

Zhou W, Cunningham KA, Thomas ML (2003) Estrogen effects on the hyperactivity induced by (+)-MDMA and cocaine in female rats. Behav Neurosci 117:84-94 